\title{
Imaging cognitive reserve
}

\author{
Yaakov Stern, Nikolaos Scarmeas, and Christian Habeck \\ Taub Institute for Research in Alzheimer's Disease and the Aging Brain and the College of Physicians \\ and Surgeons of Columbia University, New York, USA
}

\begin{abstract}
$W$ e review three studies that attempt to explore the neural substrates of cognitive reserve (CR). All studies utilize two conditions of a visual recognition task: a low demand condition, and another where difficulty was titrated such that all subjects performed at $75 \%$ recognition accuracy. We hypothesized that there would be different patterns of task-related activation as a function of a proxy measure of CR. The first two studies focused on young subjects, and found either brain areas or brain networks where the amount of increased activation from low to titrated demand correlated with CR. The third study compared activation patterns of young and elderly individuals. As in the previous studies, brain areas were found in both groups where there was differential activation as a function of $\mathrm{CR}$. Most notable were locations where the relation between activation and $\mathrm{CR}$ differed across the two groups. These findings provide a basis for a preliminary neural implementation of cognitive reserve. They also suggest that there may be a reorganization of the neural implementation of reserve in normal ageing, which may constitute compensation for the neural effects of ageing.
\end{abstract}

\ ous présentons trois études qui visaient à explorer les substrats neuraux de la réserve cognitive (RC). Ces études utilisaient deux conditions d'une tâche de reconnaissance visuelle, une condition peu demandante et une autre plus difficile pour laquelle tous les participants avaient une performance avec une exactitude de reconnaissance de $75 \%$. L'hypothèse proposée était qu'il y aurait différents patrons d'activation reliée à la tâche comme fonction d'une mesure intermédiaire de la RC. Les deux premières études visaient de jeunes participants. Elles ont montré qu'à la fois les zones cérébrales et les réseaux cérébraux pour lesquels l'importance d'activation augmentée à partir de demandes faibles à élevées étaient corrélés avec la RC. La troisième étude comparait les patrons d'activation d'individus jeunes et âgés. Comme dans les études précédentes, les zones cérébrales se sont révélées être une fonction de la $\mathrm{RC}$ dans les deux groupes où il y avait une activation différentielle. Les locations où la relation entre l'activation et la RC différait entre les deux groupes est particulièrement remarquable. Ces résultats fournissent une base pour l'accomplissement neural préliminaire de la RC. Ils suggèrent également qu'il peut y avoir une réorganisation de ces accomplissements neuraux de réserve dans le vieillissement normal, lequel peut constituer une compensation pour les effets neuraux associés au vieillissement.

S e revisan tres estudios que exploran los substratos neurales de la reserva cognitiva (RC). Todos los estudios $\mathcal{N}$ utilizan dos condiciones en una tarea de reconocimiento visual, una condición de baja demanda y otra condición de alta demanda. Todos sujetos tuvieron un nivel de $75 \%$ de aciertos en el reconocimiento. Se postularon hipótesis que proponen que habría diferentes patrones de activación en las tareas como una función de una medida proxy de RC. Los dos primeros estudios se enfocaron en sujetos jóvenes, y se encontraron tanto áreas como redes cerebrales donde la cantidad de incremento en la activación, de la condición baja a la de alta demanda se correlacionó con la RC. El tercer estudio comparó los patrones de activación de individuos jóvenes y mayores. Como en los estudios previos, se encontraron áreas cerebrales en ambos grupos, donde hubo una activación diferencial en función de la RC. Se detectaron regiones donde la relación entre la activación y la RC fueron diferentes entre los grupos. Estos resultados sugieren datos para poder explorar las bases neuronales de la reserva cognitiva. También sugieren que durante el envejecimiento normal puede existir una reorganización neuronal de la RC, el cual forma parte de una compensación por las consecuencias neurales del envejecimiento.

Correspondence should be sent to Yaakov Stern, 630 West $168^{\text {th }}$ Street, P\&S Box 16, New York, NY, 10032, USA (E-mail: ys11@columbia.edu).

This work was supported by NIH grant AG 14671.

(C) 2004 International Union of Psychological Science 
The idea of cognitive reserve (CR) stems from the repeated observation that there does not appear to be a direct relationship between the degree of brain pathology or brain damage and the clinical manifestation of that damage. There are two concepts that we have proposed as an account for the neurophysiological substrate of CR. In the past, we have tried to differentiate between these two ideas, calling one reserve and the other compensation (Stern, 2002). The concept of reserve is based on the variability that naturally exists across individuals in the ability to recruit brain networks in response to challenging tasks. This variability might be translated into differential susceptibility to factors that disrupt performance, i.e., differential reserve. A related idea is that once pathology disrupts the brain networks that normally underlie performance, people may adapt new, compensatory networks. We call this compensation. Both reserve and compensation fall under the rubric of cognitive reserve.

Figure 1 attempts to illustrate our differential conception of reserve and compensation. In each graph in the figure, the $\mathrm{X}$-axis indicates increasing task load and the $\mathrm{Y}$-axis indicates expression of some brain area or brain network during task performance. Some possible sets of relationships between these variables are illustrated. In a young individual where there is no brain pathology, we would expect increased network expression as task load increases. At some point, expression of this network may plateau, and perhaps an additional network may become active at this higher difficulty level. In the nomenclature we propose, both of these networks would be subsumed under the term "reserve." These are networks that underlie task performance and are invoked as an individual is challenged by a task. We would hypothesize that individuals with more efficient networks, or those who are better able to activate additional networks as difficulty increases, would have more flexibility in coping with challenges. Furthermore, if there were brain pathology, these individuals would be more able to cope with this pathology and continue to operate effectively. On the right of the figure are two examples of what might happen when pathology occurs. In the top example, an older individual, or one with pathology, continues to use the same networks, albeit with less efficiency. There are some differences in how the networks are activated as a function of task difficulty. The first network plateaus much sooner. We could say that it is less efficient in that it needs to be activated at a lower level of load. The second network is expressed to a lesser degree than in young subjects. This could be an indication of lowered capacity in that the person with brain damage is less able to invoke the network. However, in both cases, the individual with brain damage is still using the same network as the person without brain damage. We would say that they are using reserve networks.

The lower right-hand figure illustrates an alternate scenario, where the individuals with brain damage express an entirely different network to

\section{Young}
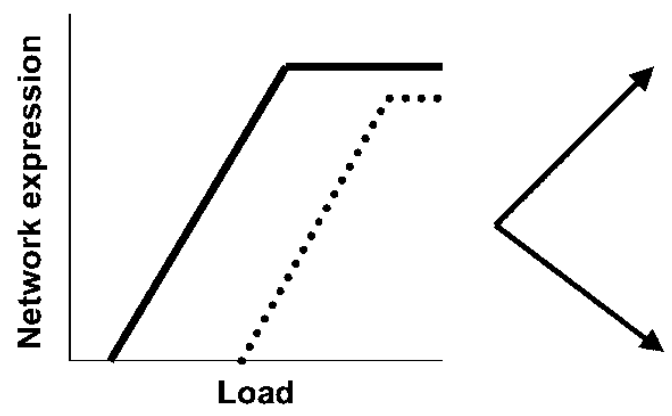

Reserve network 1
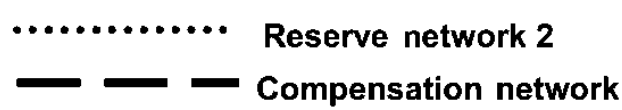

\section{Brain pathology/Ageing}
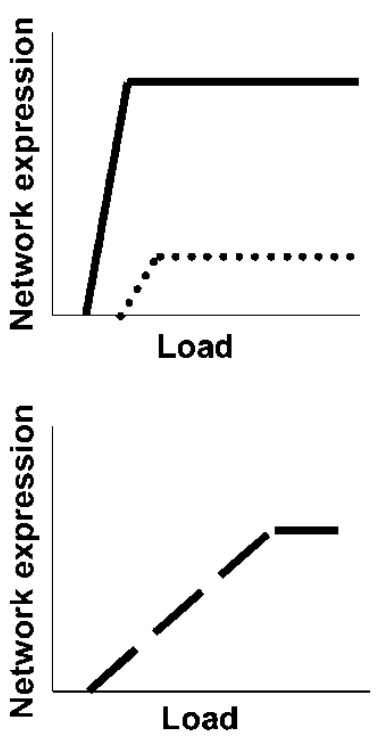

Figure 1. Theoretical representation of reserve and compensation networks. 
the young subjects. This network meets our operational definition for compensation in that it is not expressed in the young subjects. The term "compensation" in our nomenclature does not indicate whether the compensatory network actually allows the individual to work at the same level as someone without brain pathology. This is something that can be assessed separately from whether a compensatory network is present or not.

The distinction between reserve and compensatory networks emerges from consideration of findings and functional imaging studies that compare task-related activation in impaired and unimpaired groups. Often, imaging studies comparing an impaired and an unimpaired group will find greater activation in some brain area in the impaired group (Backman, Andersson, Nyberg, Winblad, Nordberg, \& Almkvist, 1999; Becker, Mintun, Aleva, Wiseman, Nichols, \& DeKosky, 1996; Cabeza, Anderson, Houle, Mangels, \& Nyberg, 2000; Grady et al., 1993, 1994, 1996; Logan, Sanders, Snyder, Morris, \& Buckner, 2002; Madden et al., 1999; McIntosh et al., 1999; Reuter-Lorenz, 2002; Reuter-Lorenz et al., 2000; Stern et al., 2000). This is often interpreted as the impaired group compensating for pathology by engaging alternate brain areas during task performance. If compensation truly represents a change that is induced by the brain damage, then it is important to distinguish between compensation and reserve. Without careful consideration, it is possible to interpret increased activation in an impaired group as compensation when it is not. As our graphs suggest, there may be increased network expression with increased task difficulty. This has been noted often in imaging studies (e.g., Glahn et al., 2002; Grady et al., 1996; Jansma, Ramsey, Coppola, \& Kahn, 2000; Jha \& McCarthy, 2000; Rypma \& D'Esposito, 1999). It is common for a task to be more difficult in an impaired group than in an unimpaired group. Therefore, the differential activation that is seen in an impaired group may simply be a function of increases in task difficulty. That is, after matching for task difficulty across the two groups, one might find that the two groups are actually using the same network, not different networks.

The support for the concept of $\mathrm{CR}$ in ageing and Alzheimer's disease (AD) comes from both epidemiologic and imaging studies. Epidemiological data suggests that high education, occupation (Stern, Gurland, Tatemichi, Tang, Wilder, \& Mayeux, 1994), or more active engagement in intellectual, social, and physical activities (Fabrigoule, Letenneur, Dartigues, Zarrouk, Commenges, \& Barberger-Gateau, 1995; Friedland, Fritsch, \& Smyth, 2001; Kondo, Niino, \& Shido, 1994; Scarmeas, Levy, Tang, Manly, \& Stern, 2001; Wilson et al., 2002) are associated with decreased risk for incident dementia. Similar epidemiological data suggests that increased CR might also reduce the risk of the cognitive changes that occur in normal ageing. It has been reported that individuals with higher levels of intellectual ability, education, and socioeconomic status are more likely to develop an engaged lifestyle, which in turn contributes to the maintenance of verbal intelligence in later life (Gold, Andres, Etezadi, Arbuckle, Schwartzman, \& Chaikelson, 1995). In another study, among other factors, education was related to maintenance of intellectual performance in a sample of Second World War veterans tested twice over a 40-year period (Arbuckle, Gold, Andres, Schwartzman, \& Chaikelson, 1992). Low education has been associated with poor health and function in older adults (Snowdon, Ostwald, \& Kane, 1989a; Snowdon, Ostwald, Kane, \& Keenan, 1989b) as well as with a faster rate of cognitive decline (Butler, Ashford, \& Snowdon, 1996; Nguyen, Black, Ray, Espino, \& Markides, 2002).

Supporting the concept of CR, PET studies in $\mathrm{AD}$ subjects matched for clinical severity have reported negative correlations between resting cerebral blood flow (with CBF; taken as a surrogate for AD pathology) (DeCarli et al., 1992; Friedland, Brun, \& Bundinger, 1985; McGeer, McGeer, Harrop, Akiyama, \& Kamo, 1990) and education, IQ, occupation, and leisure (Alexander, Furey, Grady, Pietrini, Mentis, \& Schapiro, 1997; Stern, Alexander, Prohovnik, \& Mayeux, 1992; Stern et al., 1995). The negative correlations are consistent with the prediction that at any given level of behavioural symptomatology, a subject with a higher level of $\mathrm{CR}$ should have greater AD pathology (i.e., lower CBF).

While these studies and others provide support for the concept of $\mathrm{CR}$, its neurophysiological substrate has not been established. Since we have proposed that differential $\mathrm{CR}$ is associated with different ways of processing task demands, this would predict that differential task-related neural processing in individuals of any given age would be a function of CR. These activation differences across subjects should be present not only in individuals affected by brain pathology, but even in healthy young individuals. 
In this review, we will describe three studies that have attempted to identify the neurophysiological substrate underlying a cognitive reserve. The first two focus on young, healthy individuals. Testing for a relationship between a cognitive reserve index such as IQ and differential activation in young subjects has the advantage that one need not be concerned about the confound of a cross-subject variability in age-related brain pathology. These two studies focus on reserve. The third study compares activation in old and young subjects. This study comparison allows us to search for compensatory networks in ageing.

All three studies used a continuous nonverbal recognition task. The basic task consists of the serial presentation of one or more single unnameable shapes, followed by a series of the same number of recognition probes. For each probe, the subject used a button press to indicate whether or not they had just seen the item. There were two task conditions. In the low demand condition, each study item was followed by a recognition probe. In the titrated demand condition, subjects studied a longer list of items, and then responded to an equally long set of recognition probes. Prior to scanning, the study list size of the titrated demand condition was adjusted for each subject, such as recognition accuracy with $75 \%$. This procedure was intended to match task difficulty (as operationalized by performance) across subjects.

Our intention was to explore how individual differences in cognitive reserve are related to changes in neural activity as the subjects move from the low to the titrated demand task. Our prediction was that certain aspects of task-related activation would be related to cognitive reserve. This simplifies to a prediction that there will be a correlation between fMRI activation and a measure of cognitive reserve.
The first study (Stern, Zarahn, Hilton, Delapaz, \& Rakitin, 2003) used 19 healthy young adults between the ages of 18 and 30 years. We used the raw score of the National Adult Reading Test (NART; Nelson, 1982; Grober \& Sliwinski, 1991) as a proxy measure for cognitive reserve. This test is a good estimate of verbal IQ, and reading measures have been used effectively as measures of reserve in the past. The data analytic approach in this study was to look voxel by voxel to find brain areas where there was a correlation between individual subject's NART scores and the degree to which event-related fMRI response amplitude changed from the low to the titrated demand. During the study phase of the task (i.e., when subjects were viewing the shapes to remember them later), positive correlations between titrated minus low demand activation and NART were seen in left middle frontal gyrus and negative correlations were seen at right superior frontal gyrus, middle frontal gyrus, precentral gyrus, medial frontal gyrus, and insular. Figure 2 demonstrates this correlation between task-related activation and NART for one brain area, left middle frontal gyrus. Note the relationship individual by individual between task-related activation and NART scores. We also found brain areas that showed similar relationships between task activation and NART scores during the recognition phase of the task.

The primary finding of this study was that, both during the study and during subsequent retrieval, brain areas were noted where there was a systematic relationship between $\mathrm{CR}$ and brain activation. These correlations support our hypothesis that neural processing differs as a function of CR. This differential processing may help explain individual differences in capacity or efficiency, and may underlie reserve against age-related or other pathologic changes.
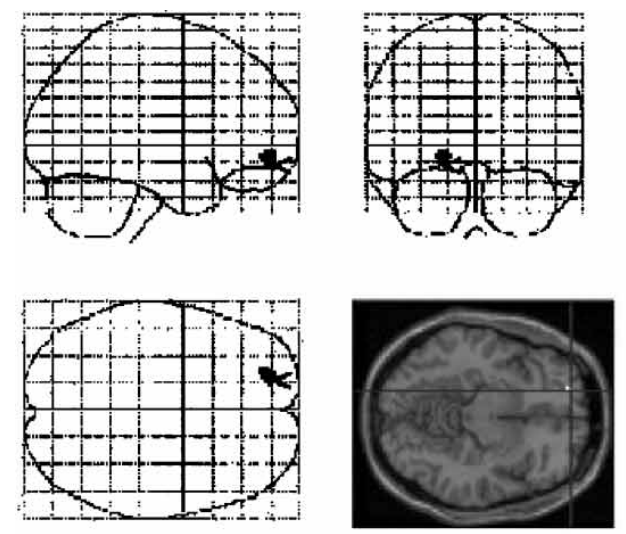

Titrate Study - Low Study NART correct at [-20 56 -10]

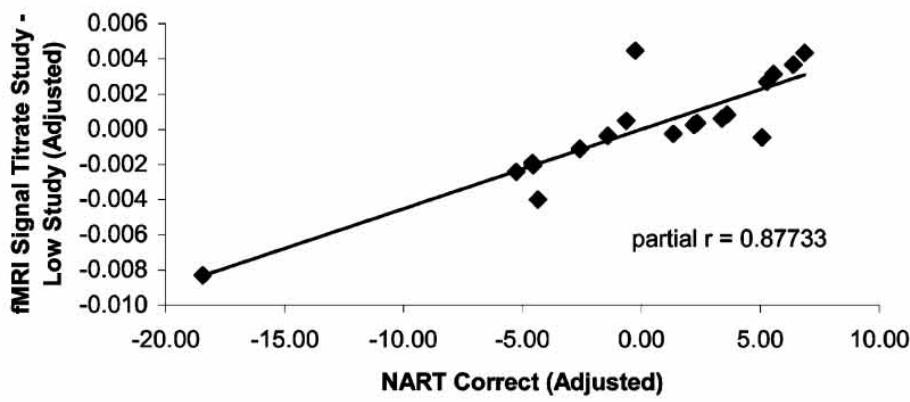

Figure 2. Left: Area where titrated minus low demand activation during study of shape stimuli correlated positively with NART score in young subjects. Right: The scatter graph illustrates this correlation at a selected voxel. 
In a subsequent study, we evaluated 17 healthy young adults, using the same activation methodology (Habeck, Hilton, Zarahn, Flynn, Moeller, $\&$ Stern, 2003). The major difference was in how we analysed the functional imaging data. In this second study we used ordinal trend canonical variates analysis (OrT CVA) (Habeck, Stern, Posner, \& Moeller, 2002). This analysis is methodologically similar to other regional covariance analysis techniques, and is designed to identify a covariance pattern (or "brain network") whose expression increases from the low to titrated demand condition for as many subjects as possible. The ordinal trend analysis was first performed on imaging data from the study phase of the task. Once such a brain network, whose subject expression systematically increased in expression from low to titrated demand, was identified, we examined the relationship between individual subjects' change in network expression across the two conditions and their NART scores.

During the study phase of the task, we identified a covariance pattern, or brain network, whose change in expression from the low to the titrated demand condition increased for 15 of the 17 subjects. This is demonstrated in Figure 3, where each line represents subject expression across the two conditions. This brain network reflects activity in all areas of the brain; however, some areas are more involved in this network
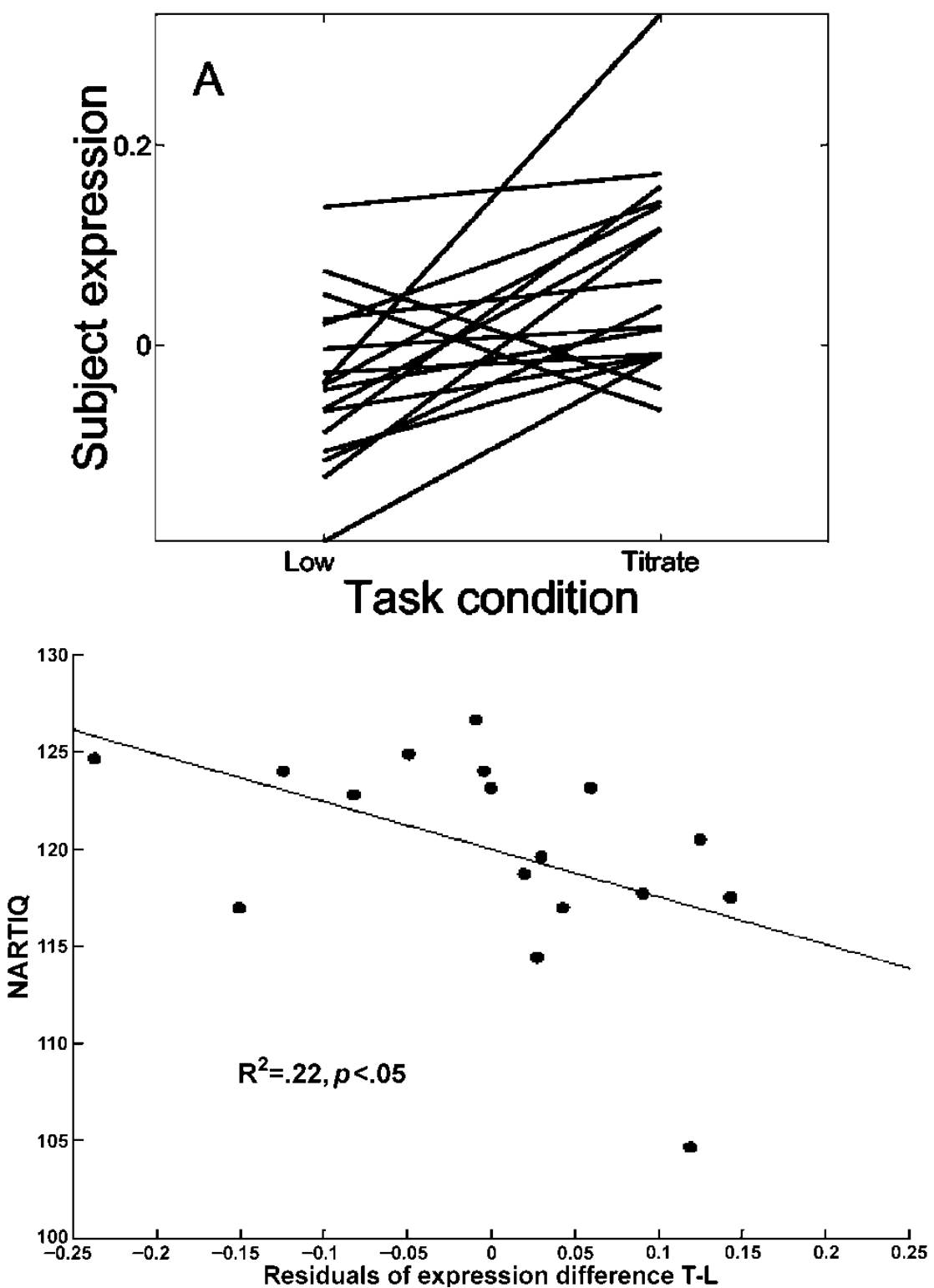

Figure 3. Expression of a covariance pattern found during study of shape stimuli. Top: expression of the network increased from low to titrated demand in 15 of 17 subjects. Bottom: Subject's change in expression of this network across conditions correlated negatively with NART IQ. 
than others. Further, because this network described a covariance pattern, it implies that change in activation in one area is related to change in another area. This relationship can be positive or negative. Thus, as the brain network expression increases, some brain areas show increased activation and some areas show decreased activation. Areas that were associated with increases in activation from the low to the titrated condition for the majority of subjects were found in cerebellar locations. Areas associated with decreased activity from the low to the titrated demand condition were attained in precuneus, anterior singular gyrus, bilateral thalamus, right insular, right middle temporal gyrus, and bilateral inferior frontal gyrus.

The key finding for our purposes was that the larger the increase in activation from the low to the titrated demand condition in a subject, the lower their NART IQ. That is, subjects with CR showed the greatest changes in expression of this network across the two difficulty conditions. These findings were independent of any differences in the study list size across subjects. This correlation is illustrated in Figure 3.

Once a brain network is identified in one task condition, one can apply it prospectively to data from another task condition and investigate the association of network expression with other experimental variables. In this case, we determined whether the network that we identified during study also changed its subject expression from the low to the titrated demand condition during the recognition phase of the task. Indeed, we found that network expression increased from low to titrated demand during recognition in the same manner as it did during encoding. Further, across subjects, the change in expression from the low to the titrated demand condition in the test phase again correlated significantly with NART IQ.

Thus, in the second study, a brain network was found that showed increased expression as the load associated with the task increased. That is, as we moved from a low demand task to a titrated demand task, increased expression of this network was noted. Further, this change in activation across tasks was associated with CR: Individuals with lower CR showed greater levels change in network expression. These results complement those of the first study. We have now found a brain network that appears to be differentially expressed as a function of CR.

The third study (Scarmeas et al., 2003) used the same activation task. In this study we used PET as the imaging modality, and both old and young subjects were included. Seventeen young adults and 19 healthy elderly adults participated. The cognitive reserve variable that we used in this study was a factor score that summarized years of education and scores on two IQ indices, the NART and WAIS-R vocabulary score. As in the other studies, subjects were scanned while performing the low and titrated demand tasks.

This study used a similar analytic approach to the first study. We began by searching for voxels where there was a correlation between the CR measure and the change in activation from the low to the titrated condition. As in our initial study, areas where such a correlation is found would be likely candidates to be mediating CR . Indeed, we found such areas both in the young and the old subjects. The more crucial theoretical point in this study, however, was to search for areas where the relationship between the taskrelated activation and cognitive reserve differed in young and old subjects. For example, Figure 4 illustrates a voxel in the right inferior temporal gyrus, where the relationship between task-related activation and CR was positive in the young, and negative in the old. If we assume that people with more $\mathrm{CR}$ are doing a task in a more optimal manner, then the positive relationship in the young would suggest that it is more adaptive to show increased activation at this brain location as a task gets more difficult. However, the older subjects with more reserve are doing exactly the opposite. This finding suggests that there has been some reorganization of the networks underlying task performance in the old subjects versus the young subjects. This reorganization has resulted in the optimal activation of this brain area in old subjects with high reserve being in the opposite direction to that in young subjects with high reserve. The older subjects are using a brain area differently to the younger subjects in order to compensate for the effects of ageing. We hypothesize that the source of this change in brain utilization is the age-related neural changes in the older group. This change in network utilization would be a candidate for what we have termed "compensation."

Thus, this third study points to a set of brain areas where there may be reorganization of brain responses as a response to ageing. We see this as a first step in understanding the neural substrates of compensation.

In summary, the three studies reviewed represent first steps in identifying the neural implementation of the concepts of reserve and compensation. We have begun with a nonverbal 


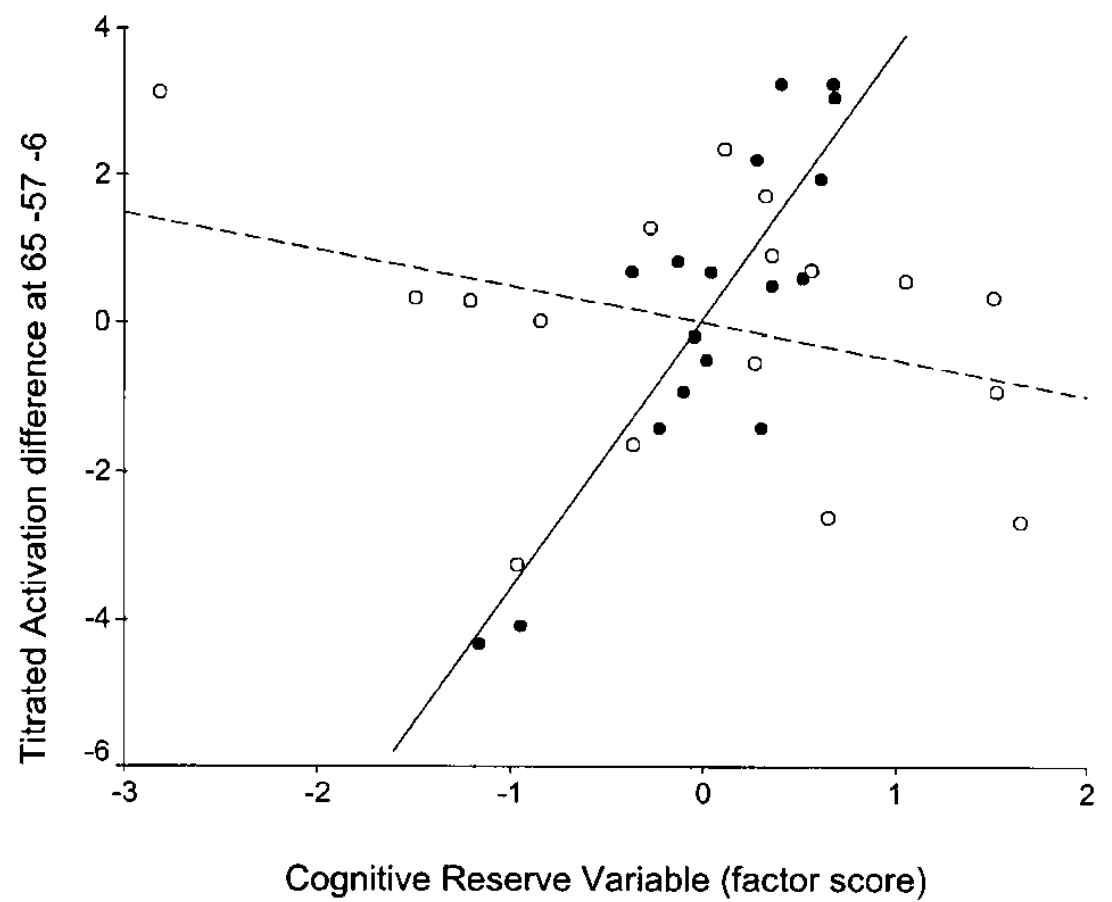

Figure 4. In right inferior temporal gyrus, change in activation from the low to the titrated demand condition correlated positively with an index of CR in young subjects, and negatively in old subjects.

memory task, but plan to generalize our application of these concepts to other tasks as well. If cognitive reserve, as we conceive of it, allows people to cope with brain pathology and maintain effective functioning, then its implementation should not be specific to any particular task.

However, there are certain aspects of our study design that we view as key to exploring reserve and compensation. The first one is careful control of task difficulty. Without this, we cannot be sure that between-subject differences and activation are not simply a function of differences in the difficulty of the task for each subject. This is the reason why we attempted to use a titration procedure to match task difficulty for each subject. A second one involves analytic techniques that allow us to compare the relationship between task-related activation and reserve across groups. We feel that both the voxel-based and network-based approaches will yield valuable information in the future.

\section{REFERENCES}

Alexander, G. E., Furey, M. L., Grady, C. L., Pietrini, P., Mentis, M. J., \& Schapiro, M. B. (1997). Association of premorbid function with cerebral metabolism in Alzheimer's disease: Implications for the reserve hypothesis. American Journal of Psychiatry, 154, 165-172.

Arbuckle, T. Y., Gold, D. P., Andres, D., Schwartzman, A., \& Chaikelson, J. (1992). The role of psychosocial context, age, and intelligence in memory performance of older men. Psychology and Aging, 7, 25-36.

Backman, L., Andersson, J. L., Nyberg, L., Winblad, B., Nordberg, A., \& Almkvist, O. (1999). Brain regions associated with episodic retrieval in normal aging and Alzheimer's disease. Neurology, 52, 1861-1870.

Becker, J. T., Mintun, M. A., Aleva, K., Wiseman, M. B., Nichols, T., \& DeKosky, S. T. (1996). Compensatory reallocation of brain resources supporting verbal episodic memory in Alzheimer's disease. Neurology, 46, 692-700.

Butler, S. M., Ashford, J. W., \& Snowdon, D. A. (1996). Age, education, and changes in the MiniMental State Exam scores of older women: Findings from the Nun Study. Journal of the American Geriatrics Society, 44, 675-681.

Cabeza, R., Anderson, N. D., Houle, S., Mangels, J. A., \& Nyberg, L. (2000). Age-related differences in neural activity during item and temporal-order memory retrieval: A positron emission tomography study. Journal of Cognitive Neurosciences, 12, 197-206.

DeCarli, C., Atack, J. R., Ball, M. J., Kay, J. A., Grady, C. L., Fewster, P., Pettigrew, K. D., Rapoport, S. I., \& Schapiro, M. B. (1992). Postmortem regional neurofibrillary tangle densities but not senile plaque densities are related to regional cerebral metabolic rates for glucose during life in Alzheimer's disease patients. Neurodegeneration, 1, 113-121.

Fabrigoule, C., Letenneur, L., Dartigues, J. F., Zarrouk, M., Commenges, D., \& BarbergerGateau, P. (1995). Social and leisure activities and risk of dementia: A prospective longitudinal study. Journal American Geriatrics Society, 43, 485-490.

Friedland, R. P., Brun, A., \& Bundinger, T. F. (1985). 
Pathological and positron emission tomographic correlations in Alzheimer's disease. Lancet, 1-228.

Friedland, R. P., Fritsch, T., \& Smyth, K. A. (2001). Patients with Alzheimer's disease have reduced activities in midlife compared with healthy controlgroup members. Proceedings of the National Academy of Sciences, USA, 98, 3440-3445.

Glahn, D. C., Kim, J., Cohen, M. S., Poutanen, V. P., Therman, S., Bava, S., Van Erp, T. G. M., Manninen, M., Huttunen, M., Lonnqvist, J., Standertskjold-Nordenstam, C. G., \& Cannon, T. D. (2002). Maintenance and manipulation in spatial working memory: Dissociations in the prefrontal cortex. Neuroimage, 17, 201-213.

Gold, D. P., Andres, D., Etezadi, J., Arbuckle, T., Schwartzman, A., \& Chaikelson, J. (1995). Structural equation model of intellectual change and continuity and predictors of intelligence in older men. Psychology and Aging, 10, 294-303.

Grady, C. L., Haxby, J. V., Horwitz, B., Gillette, J., Salerno, J. A., Gonzalez-Aviles, A., Carson, R. E., Herscovitch, P., Schapiro, M. B., \& Rapoport, S. I. (1993). Activation of cerebral blood flow during a visuoperceptual task in patients with Alzheimer-type dementia. Neurobiology of Aging, 14, 35-44.

Grady, C. L., Horwitz, B., Pietrini, P., Mentis, M. J., Ungerleider, L. G., Rapoport, S. I., \& Haxby, J. V. (1996). Effect of task difficulty on cerebral blood flow during perceptual matching for faces. Human Brain Mapping, 4, 227-239.

Grady, C. L., Maisog, J. M., Horwitz, B., Ungerleider, L. G., Mentis, M. J., Salerno, J. A., Pietrini, P., Wagner, E., \& Haxby, J. V. (1994). Age-related changes in cortical blood flow activation during visual processing of faces and location. Journal of Neurosciences, 14, 1450-1462.

Grober, E., \& Sliwinski, M. (1991). Development and validation of a model for estimating premorbid verbal intelligence in the elderly. Journal of Clinical and Experimental Neuropsychology, 13, 933-949.

Habeck, C., Hilton, H. J., Zarahn, E., Flynn, J., Moeller, J. R., \& Stern, Y. (2003). Relation of cognitive reserve and task performance to expression of regional covariance networks in an event-related fMRI study of non-verbal memory. Neuroimage, 20, 1723-1733.

Habeck, C. G., Stern, Y., Posner, H. B., \& Moeller, J. R. (2002). Regional covariance analysis of event-related fMRI, SFN Abstracts.

Jansma, J. M., Ramsey, N. F., Coppola, R., \& Kahn, R. S. (2000). Specific versus nonspecific brain activity in a parametric n-back task. Neuroimage, 12, 688-697.

Jha, A. P., \& McCarthy, G. (2000). The influence of memory load upon delay-interval activity in a working-memory task: An event-related functional MRI study. Journal of Cognitive Neuroscience, 12, 90-105.

Kondo, K., Niino, M., \& Shido, K. (1994). A casecontrol study of Alzheimer's disease in Japansignificance of life-styles. Dementia, 5, 314-326.

Logan, J. M., Sanders, A. L., Snyder, A. Z., Morris, J. C., \& Buckner, R. L. (2002). Under-recruitment and nonselective recruitment: Dissociable neural mechanisms associated with aging. Neuron, 33, 827-840.

Madden, D. J., Turkington, T. G., Provenzale, J. M.,
Denny, L. L., Hawk, T. C., Gottlob, L. R., \& Coleman, R. E. (1999). Adult age differences in the functional neuroanatomy of verbal recognition memory. Human Brain Mapping, 7, 115-135.

McGeer, E. G., McGeer, P. L., Harrop, R., Akiyama, H., \& Kamo, H. (1990). Correlations of regional postmortem enzyme activities with premortem local glucose metabolic rates in Alzheimer's disease. Journal of Neurosciences Research, 27, 612-619.

McIntosh, A. R., Sekuler, A. B., Penpeci, C., Rajah, M. N., Grady, C. L., Sekuler, R., \& Bennett, P. J. (1999). Recruitment of unique neural systems to support visual memory in normal aging. Current Biology, 9, 1275-1278.

Nelson, H. E. (1982). The National Adult Reading Test (NART): Test manual. Bury St Edmunds, UK: Thames Valley Test Company.

Nguyen, H. T., Black, S. A., Ray, L. A., Espino, D. V., \& Markides, K. S. (2002). Predictors of decline in MMSE scores among older Mexican Americans. Journal of the Gerontological Association, 57, M181.

Reuter-Lorenz, P. (2002). New visions of the aging mind and brain. Trends in Cognitive Science, 6, 394.

Reuter-Lorenz, P. A., Jonides, J., Smith, E. E., Hartley, A., Miller, A., Marshuetz, C., \& Koeppe, R. A. (2000). Age differences in the frontal lateralization of verbal and spatial working memory revealed by PET. Journal of Cognitive Neuroscience, 12, $174-187$.

Rypma, B., \& D'Esposito, M. (1999). The roles of prefrontal brain regions in components of working memory: Effects of memory load and individual differences. Proceedings of the National Academy of Sciences of the United States of America, 96, 6558-6563.

Scarmeas, N., Levy, G., Tang, M. X., Manly, J., \& Stern, Y. (2001). Influence of leisure activity on the incidence of Alzheimer's disease. Neurology, 57, 2236-2242.

Scarmeas, N., Zarahn, E., Anderson, K. E., Hilton, H. J., Flynn, J., Van Heertum, R. L., Sackeim, H. A., \& Stern, Y. (2003). Cognitive reserve modulates functional brain responses during memory tasks. A PET study in healthy young and elderly subjects. Neuroimage, 19, 1215-1227.

Snowdon, D. A., Ostwald, S. K., \& Kane, R. L. (1989a). Education, survival and independence in elderly Catholic sisters, 1936-1988. American Journal of Epidemiology, 130, 999-1012.

Snowdon, D. A., Ostwald, S. K., Kane, R. L., \& Keenan, N. L. (1989b). Years of life with good and poor mental and physical function in the elderly. Journal of Clinical Epidemiology, 42, 1055-1066.

Stern, Y. (2002). What is cognitive reserve? Theory and research application of the reserve concept. Journal of the International Neuropsychological Society, 8, 448-460.

Stern, Y., Alexander, G. E., Prohovnik, I., \& Mayeux, R. (1992). Inverse relationship between education and parietotemporal perfusion deficit in Alzheimer's disease. Annals of Neurology, 32, 371-375.

Stern, Y., Alexander, G. E., Prohovnik, I., Stricks, L., Link, B., Lennon, M. C., \& Mayeux, R. (1995). Relationship between lifetime occupation and parietal flow: Implications for a reserve against Alzheimer's disease pathology. Neurology, 45, 55-60.

Stern, Y., Gurland, B., Tatemichi, T. K., Tang, M. X., 
Wilder, D., \& Mayeux, R. (1994). Influence of education and occupation on the incidence of Alzheimer's disease. Journal of the American Medical Association, 271, 1004-1010.

Stern, Y., Moeller, J. R., Anderson, K. E., Luber, B., Zubin, N. R., DiMauro, A. A., Park, A., Campbell, C. E., Marder, K., Bell, K., Van Heertum, R., \& Sackeim, H. A. (2000). Different brain networks mediate task performance in normal aging and AD: Defining compensation. Neurology, 55, 1291-1297.
Stern, Y., Zarahn, E., Hilton, H. J., Delapaz, R., \& Rakitin, B. (2003). Exploring the neural basis of cognitive reserve. Journal of Clinical and Experimental Neuropsychology, 5, 691-701.

Wilson, R. S., Mendes De Leon, C. F., Barnes, L. L., Schneider, J. A., Bienias, J. L., Evans, D. A., \& Bennett, D. A. (2002). Participation in cognitively stimulating activities and risk of incident Alzheimer disease. Journal of the American Medical Association, $287,742-748$. 